\title{
Isolation and characterization of an antifungal compound 5-hydroxy-7,4'- dimethoxyflavone from Combretum zeyheri
}

Rumbidzai Mangoyi ${ }^{1}$, Jacob Midiwo ${ }^{2}$ and Stanley Mukanganyama ${ }^{1 *}$

\begin{abstract}
Background: Combretum zeyheri, belongs to the family Combretaceae and is one of the most popular herbal plants in tropical and subtropical countries. The leaves of Combretum zeyheri have been used as herbal medicine and have been reported to have pharmacological activity which includes anti-bacterial, anti-fungal, anticancer and antioxidant properties. The goal of this study was to isolate, identify and characterize compounds from C. zeyheri leaves which are responsible for its antifungal activity.
\end{abstract}

Methods: The preliminary isolation of C. zeyheri active compounds was carried out using chromatographic techniques which include sephadex gel column chromatography, silica gel column chromatography and thin-layer chromatography $(\mathrm{TLC})$. The isolated compounds were then investigated for their antifungal activity using broth dilution assay. The combined effect of the most potent compound and an antifungal drug miconazole was investigated using the checkerboard assay. Time-kill assays were conducted for the combinations using the colony counting method. The mechanism of action of 5-hydroxy-7,4'-dimethoxyflavone as a potent antifungal agent was investigated by determining its inhibitory activity on Candida albicans drug efflux pumps using the ciprofloxacin assay. The ability of 5-hydroxy-7,4'-dimethoxyflavone to inhibit antioxidant enzymes as well as the biosynthesis of ergosterol were also investigated.

Results: A total of four pure compounds (A-D) were isolated from C. zeyheri leaf extract. Compound B (5-hydroxy-7,4'-dimethoxyflavone) was found to be active against Candida albicans using broth dilution method. This compound was also found to have synergistic activity on growth of $C$. albicans when combined with miconazole, completely inhibiting growth after only 4 hrs of incubation. Analysis of ergosterol content from Candida albicans showed a time-dependent decrease to $91 \%$ and $63 \%$ at 16 and 24 hrs respectively, in cells treated with $1 / 2$ MIC of 5-hydroxy-7,4'-dimethoxyflavone. The compound 5-hydroxy-7,4'-dimethoxyflavone also showed inhibition of both the drug efflux pumps (with $\mathrm{IC}_{50}=51.64 \mu \mathrm{g} / \mathrm{ml}$ ) and the antioxidant enzymes (at $5 \mu \mathrm{M}$ ).

Conclusion: The compound 5-hydroxy-7,4'-dimethoxyflavone may be partly responsible for the reported antifungal activity of $C$. zeyheri, and may serve as a potential source of lead compounds that can be developed as antifungal phytomedicines.

Keywords: Combretum zeyheri, Antifungal, 5-hydroxy-7, 4'-dimethoxyflavone, Chromatography, Isolation

\footnotetext{
* Correspondence: smukanganyama@medic.uz.ac.zw

'Department of Biochemistry, University of Zimbabwe, P.O. Box MP 167,

Harare, Mt. Pleasant, Zimbabwe

Full list of author information is available at the end of the article
} 


\section{Background}

Since 1970s, the emergence of antifungal drug resistance has been a cause of concern in the treatment of invasive fungal infections such as candidiasis [1]. This is particularly due to increased use of triazoles in prophylactic and empiric antifungal therapy in high-risk patients [2]. Persons who are at high risk for systemic fungal infections include those who have haematological malignancies, undergoing prolonged bone marrow transplantation and chemotherapy, HIV infected patients and severely burnt patients [3]. Although many of the antifungal drugs have advanced the management of fungal infections, failure rates remain high as the discovery of the ideal antifungal agent against resistant strains has not been yet obtained $[4,5]$. Thus, there is need for better strategies to protect existing drugs and develop new classes of effective drugs to treat resistant infections.

Since 1981, researchers have paid attention to the potential of medicinal plants as alternative sources for the isolation of novel metabolites with interesting biological and pharmaceutical properties [6]. Medicinal plants have been used extensively as crude material or as pure compounds for treating various disease conditions. The World Health Organization has estimated that almost $65 \%$ of the world's inhabitants rely mainly on traditional medicines for their primary health care [7]. This is because traditional medicine has remained as the most affordable and easily accessible source of treatment in the primary healthcare system mainly in most developing countries [8].

In Africa, Combretum species are well known in traditional medicine and used for various ailments and diseases ranging from heart and worm remedies to wound dressings, treatment of the mentally ill, scorpion stings and snake bites, to fever and microbial infections [9]. Among antimicrobially active compounds isolated from Combretum species are combretastatins (bibenzyle compounds), acidic tetracyclic and pentacyclic triterpenes, ellagitannins, phenanthrenes, flavonoids, saponins and cycloartane glycosides [10].

We previously reported that Combretum zeyheri had antifungal activity against $C$. albicans and C. krusei [11]. It showed growth inhibitory activity against $C$. albicans and C. krusei with minimum inhibitory concentrations of 0.08 and $0.16 \mathrm{mg} / \mathrm{ml}$ respectively using the broth dilution method [10]. Partial bioguided fractionation of $C$. zeyheri extract by sephadex LH20 gel column chromatography enabled isolation of the fractions which were also found to have the antifungal activity as well as the drug efflux pumps inhibitory activity [12].

Combretum zeyheri has also been reported to have antimicrobial [10] and antitumor activity [13] as well as the antioxidant and anti-inflammatory activity [14]. Thus, these previous findings show that $C$. zeyheri plant has great antimicrobial potential and may be used as a source of lead compounds for the development of antimicrobial drugs. Therefore, the objective of this study was to isolate the active antifungal compounds from the crude ethanolic leaf extract of C. zeyheri using chromatographic techniques and then investigate the mechanism of action of these active compounds.

\section{Methods}

\section{Fungi and reagents}

Reserpine, rhodamine 6G, nutrient agar, sabouraud dextrose agar (SDA), miconazole, dimethyl sulphoxide (DMSO), silica gel 60 - 120 mesh, 3-(4,5-dimethylthiazol-2-yl)-2,5-diphenyltetrazolium bromide (MTT), phenylmethylsulphonyle fluoride (PMSF), sucrose, 1chloro-2,4-dinitrobenzene (CDNB), glutathione, hydrogen peroxide $\left(\mathrm{H}_{2} \mathrm{O}_{2}\right)$, epinephrine, adrenochrome, $\mathrm{NADPH}, \mathrm{EDTA}, \mathrm{NaN}_{3}$, and glucose-6-phosphate were purchased from Sigma-Aldrich Chemical Co. (St Louis, MO, USA). The solvents used in this study including ethanol, methanol, dichloromethane, ethyl acetate, petroleum ether, hexane, were of analytical reagent grade. The water used for all experiments was of distilled grade. Candida albicans strain ATCC 10231 was a kind gift from Dr. K. Marobela (Department of Biological Sciences, University of Botswana).

\section{Plant collection}

Combretum zeyheri leaves were collected from Norton (Geographic coordinates of Norton, Zimbabwe, Latitude: $17^{\circ} 52^{\prime} 59^{\prime \prime} \mathrm{S}$, Longitude: $30^{\circ} 42^{\prime} 00^{\prime \prime} \mathrm{E}$, Elevation above sea level: $1360 \mathrm{~m}$, Mashonaland West province of Zimbabwe). The plant was classified by Mr. Christopher Chapano, a taxonomist at the National Botanic Gardens (Harare, Zimbabwe). Herbarium samples (Voucher number N6E7) were kept at the Department of Biochemistry, University of Zimbabwe.

\section{Extraction}

The preparation of plant extracts was previously described [11]. Briefly, $2 \mathrm{~kg}$ of C. zeyheri leaves were ground in a two speed blender (Cole Parmer Instrument Co., Vernon Hills, USA) and extracted with $8 \mathrm{~L}$ of absolute ethanol at room temperature. Extract was filtered through fine cloth and filtrate was decanted into preweighed labeled container. The solvent was removed under a stream of air in a fume cupboard at room temperature. The amount of solid extract was weighed and recorded.

\section{Isolation of active compounds from Combretum zeyheri}

The number of compounds present in C. zeyheri leaf extract was determined by thin layer chromatography (TLC). Briefly, a small amount of C. zeyheri plant extract 
was dissolved in dichloromethane and was deposited as a spot on the TLC plate (aluminium-backed silica gel 60 F254, Sigma Aldrich, St Lous, MO, USA). The bottom edge of the plate was placed in a solvent reservoir $(1 \%$ methanol in dichloromethane), and the solvent moved up the plate by capillary action. When the solvent front reached the other edge of the stationary phase, the plate was removed from the solvent reservoir. The separated spots were visualized with ultraviolet lamp at $366 \mathrm{~nm}$ and by placing the plate in iodine vapor. Silica gel column chromatography was then used to purify individual chemical compounds from mixtures of compounds. For the assay, a slurry was prepared of the eluent (70 \% dichloromethane in hexane) with the stationary phase powder (500 g of silica gel 60-120 mesh, Sigma Aldrich, St Louis, $\mathrm{MO}$, USA) and then carefully poured into the column (8 cm internal diameter $\times 120 \mathrm{~cm}$ length). The column was left overnight to fully pack. The leaf extract of C. zeyheri $(50 \mathrm{~g}$ ) was adsorbed on $55 \mathrm{~g}$ of silica gel and loaded into the column. This layer was topped with cotton wool to protect the shape of the organic layer from the velocity of solvents. Different solvents (70 \% dichloromethane in hexane, $80 \%$ dichloromethane in hexane, $90 \%$ dichloromethane in hexane, $100 \%$ dichloromethane, $1 \%$ methanol in dichloromethane, $2 \%$ methanol in dichloromethane, $3 \%$ methanol in dichloromethane, $5 \%$ methanol in dichloromethane) were slowly passed through the column in order of their increasing polarity, to advance the organic material. Fractions of $500 \mathrm{ml}$ were collected, vaporized and compounds present were checked by TLC. Samples which showed similar TLC profile were combined and further separation carried out using small columns $(2.5 \mathrm{~cm}$ internal diameter $\times 60 \mathrm{~cm}$ length). Each solvent of $500 \mathrm{ml}$ of $50 \%$ dichloromethane in hexane, $60 \%$ dichloromethane in hexane, $70 \%$ dichloromethane in hexane, 80 \% dichloromethane in hexane, 90 \% dichloromethane in hexane and 100 dichloromethane was slowly passed through the column as before to advance the organic compounds in order of their increasing polarity. Fractions of $40 \mathrm{ml}$ were collected, vaporized and compounds present were checked by TLC. Fractions which showed similar TLC profile were combined and further separation was carried out. For the fractions that showed presence of 3 or 2 compounds, crystallization was carried out by adding a few drops of hexane. The crystals formed were separated by filtration and their purity determined by TLC. Elucidation and characterization of the structures of the isolated compounds was carried out using ${ }^{1} \mathrm{H},{ }^{13} \mathrm{C}$ NMR techniques and UV spectroscopy.

\section{Antifungal activity determination of the isolated compounds}

The antifungal activity of the C. zeyheri isolated compounds was investigated using the 3-(4,5-dimethylthiazol- 2-yl)-2,5-diphenyltetrazolium bromide (MTT) assay, as described before [12]. Cultures of Candida species were transferred into fresh nutrient broth and $100 \mu \mathrm{l}$ of fresh culture were added to each well of a 96-well microtitre plates. The C. zeyheri isolated compounds were dissolved in DMSO and added to each well to a final concentration of $45 \mu \mathrm{g} / \mathrm{ml}$. Miconazole was used as the positive control and appropriate solvents used for dissolving the compounds were included as negative controls. Micro plates were incubated for 24 hours at $37^{\circ} \mathrm{C}$ and $100 \%$ relative humidity. As an indicator of growth $25 \mu \mathrm{l}$ of $2 \mathrm{mg} / \mathrm{ml}$ MTT was added to each of the microtitre plate wells and incubated for three hours.

\section{Determination of the effect of combining active compound with miconazole}

The antifungal activity of the isolated compound in combination with miconazole was assessed in a suspension assay by the checkerboard method. In brief, different concentrations of test compound were prepared by serial dilution and $20 \mu \mathrm{l}$ of each concentration was added to the rows of a 96-well microtitre plate in diminishing concentrations. The final concentrations of the test compound in a microtitre plate ranged from $0-90 \mu \mathrm{g} / \mathrm{ml}$. Miconazole was also added to the columns to final concentrations of $0-350 \mu \mathrm{g} / \mathrm{ml}$. A $160 \mu \mathrm{l}$ suspension of Candida strain adjusted to $1 \times 10^{6} \mathrm{cfu} / \mathrm{ml}$ was added to each well and cultured at $37^{\circ} \mathrm{C}$ for 24 hrs. The MIC of the test compound in combination with miconazole was determined using MTT as described before.

\section{Time-kill assays}

The antifungal activities of miconazole and the isolated active compound alone and in combination against $C$. albicans were determined at $0.4,8,20$ and 24 hrs of incubation at $37^{\circ} \mathrm{C}$ by colony-counting method. Candida albicans was exposed over time to active compound and miconazole alone as well as to their combinations. Test solutions were placed on a shaker and incubated at $37{ }^{\circ} \mathrm{C}$. At the predetermined time point, an aliquot of $20 \mu \mathrm{l}$ volumes were removed from each test suspension and plated on SDA for determining the colony forming units. Plates were then incubated at $37^{\circ} \mathrm{C}$ for $24 \mathrm{~h}$ in an incubator (Jeio tech, South Korea) and viable colony counts were performed. The broth (SDB) without any agent was used as the control for $C$. albicans growth at each time point.

\section{Determination of the effect of active compounds on drug efflux pumps}

Drug accumulation assays were carried out as described previously [12], using ciprofloxacin as the standard drug, to determine the effect of the isolated active compounds on $\mathrm{ABC}$ - drug efflux pumps in C. albicans. Further work was done to determine the concentration of compound 
that inhibits the activity of drug efflux pumps in C. albicans by half $\left(\mathrm{IC}_{50}\right)$. $\mathrm{IC}_{50}$ measures the effectiveness of compound as drug efflux pump inhibitor therefore, different concentrations of compound $(0-0.07) \mathrm{mg} / \mathrm{ml}$ were incorporated and the assay procedure was carried out.

\section{Determination of effect of active compound on ergosterol biosynthesis pathway}

The effect of C. zeyheri plant compound on ergosterol biosynthesis in $C$. albicans was investigated by quantifying the amount of ergosterol produced by C. albicans in the presence and absence of the test compound at time intervals in vitro. Briefly, a single C. albicans colony from an overnight Sabouraud dextrose agar plate culture was used to inoculate each of the two flasks containing $400 \mathrm{ml}$ of Sabouraud dextrose broth. The cells were grown until an OD of 0.5 was reached then C. zeyheri compound was added to one flask. The cultures were incubated at $37{ }^{\circ} \mathrm{C}$ and then $100 \mathrm{ml}$ aliquots were withdrawn from each flask after 16 hrs and 24 hrs. The cells were harvested by centrifugation at $1077 \times \mathrm{g}$-force for 5 min and washed once with sterile distilled water. Ten millilitres of $25 \%$ alcoholic potassium hydroxide solution $(25 \mathrm{~g}$ of $\mathrm{KOH}$ and $35 \mathrm{ml}$ of sterile water, brought to $100 \mathrm{ml}$ with $100 \%$ ethanol) were added to each pellet and vortex mixed for $1 \mathrm{~min}$. Cell suspensions were transferred to sterile tubes and incubated in an $85{ }^{\circ} \mathrm{C}$ water bath for $1 \mathrm{~h}$. Following incubation, tubes were allowed to cool to room temperature. Sterols were extracted by adding a mixture of $4 \mathrm{ml}$ sterile water and $10 \mathrm{ml}$-hexane followed by vigorous vortex mixing for $3 \mathrm{~min}$. The hexane layer was transferred to a clean tube and ergosterol content quantified spectrophotometrically at $293 \mathrm{~nm}$ using Unico UV-2800 spectrophotometer (UNICO United Products and Instruments Inc, Dayton, United States). The standard curve was used estimate the concentration of ergosterol produced in the absence and presence of C. zeyheri plant compound. For standards preparations, briefly, a stock solution of ergosterol $(0.667 \mathrm{mg} / \mathrm{ml})$ was diluted with ethanol to obtain concentrations of $0.01,0.02,0.03,0.04$ and $0.05 \mathrm{mg} / \mathrm{ml}$ and absorbances read spectrophotometrically.

\section{Determination of effect of active compound on $C$. albicans antioxidant enzymes}

Candida albicans cells grown overnight at $37{ }^{\circ} \mathrm{C}$ in the presence of isolated antifungal active compound $(50 \mu \mathrm{g} / \mathrm{ml})$ were harvested by centrifugation and then suspended in homogenizing buffer $(1 \mathrm{mmol} / \mathrm{L}$ phenylmethylsulphonyle fluoride, $250 \mathrm{mmol} / \mathrm{L}$ sucrose, $10 \mathrm{mmol} / \mathrm{L}$ Tris-HCl, pH 7.5). The control sample was also prepared and did not contain the active compound. The cells were then mechanically disrupted at $4{ }^{\circ} \mathrm{C}$ using a soniprobe (Polytron PT-MR
3000, Kinematica AG, Littau, Switzerland). The homogenate was collected and centrifuged at $20217 \times$ g-force for 1 hour at $4{ }^{\circ} \mathrm{C}$. The supernatant was collected and investigated for its protein concentration and antioxidant enzyme activity.

\section{Protein determination}

The concentration of the antioxidant enzymes produced in the presence of $C$. zeyheri antifungal active compound was determined by the Lowry method [15]. A standard curve was generated from the concentrations of bovine serum albumin (BSA) standards and used to find the concentrations of the samples from their absorbances.

\section{Glutathione-S-transferases}

GST activity was determined spectrophotometrically by measuring the formation of glutathione (GSH) and 1chloro-2,4-dinitrobenzene (CDNB) conjugate at $340 \mathrm{~nm}$ [16]. One unit of GST activity is defined as the amount of enzyme producing $1 \mu \mathrm{mol}$ of GS-DNB conjugate/min under the conditions of the assay. In this experiment, the assay mixture was placed in a $1 \mathrm{~mL}$ cuvette and consisted of potassium phosphate buffer $\mathrm{pH} 6.5(875 \mu \mathrm{l})$, $50 \mu \mathrm{l}$ of $20 \mathrm{mM}$ glutathione, $50 \mu \mathrm{l}$ of $20 \mathrm{mM}$ 1-chloro2,4-dinitrobenzene (dissolved in ethanol), and 25 and $100 \mu \mathrm{l}$ of supernatant. The reference cuvette contained everything except the supernatant being assayed. Results were expressed as nanomoles CDNB conjugate formed per minute per milligram protein by using a molar extinction coefficient of $9.6 \times 10^{3}$ mol. $\mathrm{L}^{-1} . \mathrm{cm}^{-1}$.

\section{Catalases}

Catalase activity was investigated by measuring the decrease in absorbance of $\mathrm{H}_{2} \mathrm{O}_{2}$ at $240 \mathrm{~nm}$ due to hydrogen peroxide decomposition [17]. Potassium phosphate buffer $\mathrm{pH} 7.0(1960 \mu \mathrm{l}), 990 \mu \mathrm{l}$ of $20 \mathrm{mM} \mathrm{H}_{2} \mathrm{O}_{2}, 50 \mu \mathrm{l}$ of supernatant were added to a quartz cuvette. Catalase activity was calculated in terms of nanomoles of $\mathrm{H}_{2} \mathrm{O}_{2}$ consumed per minute per milligram protein using the extinction coefficient $0.081 \times 10^{-1} \mathrm{~mol} \cdot \mathrm{L}^{-1} \cdot \mathrm{cm}^{-1}$. One unit was defined as $1 \mu \mathrm{M} \mathrm{H}_{2} \mathrm{O}_{2}$ reduced per min.

\section{Superoxide dismutase}

Superoxide dismutase activity was determined using the adrenochrome assay which is based on the ability of SOD to inhibit the autoxidation of epinephrine in alkaline [18]. Briefly, during the reaction, SOD reacts with the $\mathrm{O}^{2-}$ formed during the epinephrine oxidation and therefore slows down the rate of formation of the adrenochrome as well as the amount that is formed. Because of this slowing process, SOD is said to inhibit the oxidation of epinephrine and a unit of SOD activity is defined as that amount of SOD required to cause $50 \%$ inhibition of the oxidation of the epinephrine $\left(\mathrm{SOD}_{50}\right)$. Activity 
was calculated by measuring the increase in absorbance of the solution containing $50 \mathrm{mM}$ sodium carbonate buffer $\mathrm{pH} 10.2(2685 \mu \mathrm{l}), 75 \mu \mathrm{l}$ of the supernatant, $200 \mu \mathrm{M}$ adrenochrome $(150 \mu \mathrm{l})$ and $90 \mu \mathrm{l}$ of $0.01 \mathrm{M}$ epinephrine at $480 \mathrm{~nm}$.

\section{Glutathione reductase}

Glutathione reductase activity was determined by the method in which 1 unit of GR activity is defined as the amount of the enzyme catalyzing the reduction of $1 \mu \mathrm{M}$ of NADPH per min [19]. The reaction mixture contained $1.63 \mathrm{ml}$ phosphate buffer $\mathrm{pH}$ 7.4, $0.025 \mathrm{ml}$ supernatant, $0.1 \mathrm{ml} \mathrm{NADPH}, 0.1 \mathrm{ml}$ EDTA and $0.1 \mathrm{ml}$ oxidized GSH disulphide. Enzymatic activity was calculated by measuring the disappearance of NADPH at $340 \mathrm{~nm}$ and the results were expressed as nanomoles of NADPH oxidized per minute per milligram protein.

\section{Glutathione peroxidase}

The activity of glutathione peroxidase was determined by measuring a decrease in absorbance at $340 \mathrm{~nm}$, suggestive of the disappearance of NADPH [20]. The reaction mixture consisted of $1.53 \mathrm{~mL}$ phosphate buffer (0.05 mol/L, pH 7.0), $0.1 \mathrm{~mL} 1 \mathrm{mmol} / \mathrm{L}$ EDTA, $0.1 \mathrm{~mL}$ $1 \mathrm{mmol} / \mathrm{L} \mathrm{NaN}_{3}, 0.1 \mathrm{~mL} 1 \mathrm{mmol} / \mathrm{L}$ glutathione (GSH), $0.1 \mathrm{~mL} \quad 0.2 \mathrm{mmol} / \mathrm{L} \mathrm{NADPH}, 0.01 \mathrm{~mL} \quad 0.25 \mathrm{mmol} / \mathrm{L}$ $\mathrm{H}_{2} \mathrm{O}_{2}$, and $100 \mu \mathrm{L}$ supernatant in a final volume of $2.0 \mathrm{~mL}$. The reaction was initiated by the addition of hydrogen peroxide and the enzyme activity was calculated as nanomoles of NADPH oxidized per minute per milligram protein by using a molar extinction coefficient of $6.22 \times 10^{3} \mathrm{~mol} . \mathrm{L}^{-1} \cdot \mathrm{cm}^{-1}$.

\section{Glucose-6-phosphate dehydrogenase}

Activity of Glucose-6-phosphate dehydrogenase was determined by measuring the reduction of NADP at $340 \mathrm{~nm}$ [21]. The reaction mixture contained $0.3 \mathrm{ml}$ Tris-HCI buffer, $0.1 \mathrm{ml}$ NADP, $0.1 \mathrm{ml}$ glucose-6phosphate, $0.1 \mathrm{ml} \mathrm{MgCl}_{2}, 0.02 \mathrm{ml}$ supernatant and $2.38 \mathrm{ml}$ of $\mathrm{H}_{2} \mathrm{O}$.

\section{Statistical analysis}

A comparison of the antifungal tests and efflux activity of the samples with the standard efflux inhibitor, reserpine was evaluated by applying one way ANOVA using Dunnet's Multiple Comparison Test as the post test which compares the difference between all samples versus the control sample. All values are expressed as the mean \pm standard deviation and $P<0.05$ values or less were considered to indicate statistically significant differences. Numerical data were analysed using Graphpad ${ }^{\mathrm{Tx}}$ version 5 for Windows, (Graphpad ${ }^{\mathrm{m}}$ Software Inc., San Diego, California, USA).

\section{Results}

\section{Compounds isolated from Combretum zeyheri}

Separation of C. zeyheri plant compounds resulted in 97 different fractions which were then combined according to their TLC profile similarities (Fig. 1). Further separation by silica gel column chromatography resulted in fractions which had 3 or 2 different compounds, according to TLC profiles. Compounds were then crystallized by adding hexane and then filtered through Whatman paper. Yellow, amorphous solid crystals were observed in four fractions so they were filtered and purity of the crystals checked by TLC. Thus, four pure compounds were isolated from $C$. zeyheri and were labeled A-D. The structures of compounds $B$ and $C$ were elucidated using spectroscopic techniques and were characterized as 5hydroxy-7,4'-dimethoxyflavone and 3,5,7-trihydroxyl3,4'-dimethoxyflavone respectively (Fig. 2). ${ }^{1} \mathbf{H}$ NMR data for 5-hydroxy-7,4'-dimethoxyflavone, or compound $\mathrm{B}\left(\mathrm{CDCl}_{3}, \mathbf{4 0 0} \mathrm{MHz}\right)$ was as follows: $12.8(1 \mathrm{H}$, s,); $7.78\left(2 \mathrm{H}, \mathrm{dd}, 8 \mathrm{~Hz}, 4 \mathrm{~Hz}, \mathrm{H} 2^{\prime}\right.$ and $\left.\mathrm{H}^{\prime}\right) ; 6.97(2 \mathrm{H}$, dd, $8 \mathrm{~Hz}, 4 \mathrm{~Hz}, \mathrm{H} 3$ 'and $\left.\mathrm{H}^{\prime}\right) ; 6.52(1 \mathrm{H}, \mathrm{s}, \mathrm{H} 3) ; 6.43$ $(1 \mathrm{H}, \mathrm{d}, 4 \mathrm{~Hz}, \mathrm{H} 8) ; 6.32(1 \mathrm{H}, \mathrm{d}, 4 \mathrm{~Hz}, \mathrm{H} 6) ; 3.86(3 \mathrm{H}, \mathrm{s})$; $3.85(3 \mathrm{H}, \mathrm{s})$.

${ }^{13} \mathrm{C}$ NMR for compound $\mathrm{B}\left(\mathrm{CDCl}_{3}, \mathbf{1 0 0} \mathrm{MHz}\right): 163.9$ (C2), 104.2 (C3), 182.4 (C4), 162.0 (C5), 98.0 (C6), 165.3 (C7), 92.5 (C8), 157.6 (C9), 105.4 (C10), 123.4 (C1'), 127.9 (C2'), $114.4\left(\mathrm{C}^{\prime}\right), 162.5\left(\mathrm{C}^{\prime}\right), 114.4\left(\mathrm{C}^{\prime}\right), 127.9$ (C6'), $55.8\left(\mathrm{C6}^{\prime}-\mathrm{OCH}_{3}\right), 55.5\left(\mathrm{C} 7-\mathrm{OCH}_{3}\right)$.

${ }^{1} \mathrm{H}$ NMR data for 3,5,7-trihydroxyl-3,4'-dimethoxyflavone, or compound $\mathrm{C}$ (MeOD, $400 \mathrm{MHz}$ ) was as follows: $12.5(1 \mathrm{H}, \mathrm{s},) ; 7.76(1 \mathrm{H}, b r \mathrm{~s}) ; 7.73(1 \mathrm{H}, \mathrm{d}, 8 \mathrm{~Hz})$; $6.92(1 \mathrm{H}, \mathrm{d}, 8 \mathrm{~Hz}) ; 6.76(1 \mathrm{H}, b r \mathrm{~s}) ; 6.33(1 \mathrm{H}, \mathrm{d}, 4 \mathrm{~Hz}) ; 3.84$ $(3 \mathrm{H}, \mathrm{s}) ; 3.84(3 \mathrm{H}, \mathrm{s})$.

${ }^{13} \mathrm{C}$ NMR for compound $\mathrm{C}$ (MeOD, $100 \mathrm{MHz}$ ): 147.4 (C2), 136.6 (C3), 176.4 (C4), 160.7 (C5), 97.9 (C6), 166.3 (C7), 92.5 (C8), 156.5 (C9), 104.4 (C10), 122.3 (C1'), 115.9 (C2'), 147.8 (C3'), 149.4 (C4'), 112.0 (C5'), $122.3\left(\mathrm{C}^{\prime}\right), 56.5\left(\mathrm{C}^{\prime}-\mathrm{OCH}_{3}\right), 56.2\left(\mathrm{C} 7-\mathrm{OCH}_{3}\right)$.

\section{Antifungal activity determination of the Combretum zeyheri isolated compounds}

The four compounds that were isolated from C. zeyheri were tested for their antifungal activity and the results are shown in Fig. 3. Compound 5-hydroxy-7,4'dimethoxyflavone showed antifungal activity against $C$. albicans using the broth dilution method [10]. This is shown by a decrease in growth of the cells as indicated by a decrease in absorbance when compared to the control which contained cells only.

\section{Effect of combining 5-hydroxy-7, 4'-dimethoxyflavone with miconazole}

The in vitro combined antifungal activity of 5-hydroxy7, 4'-dimethoxyflavone with miconazole against Candida 


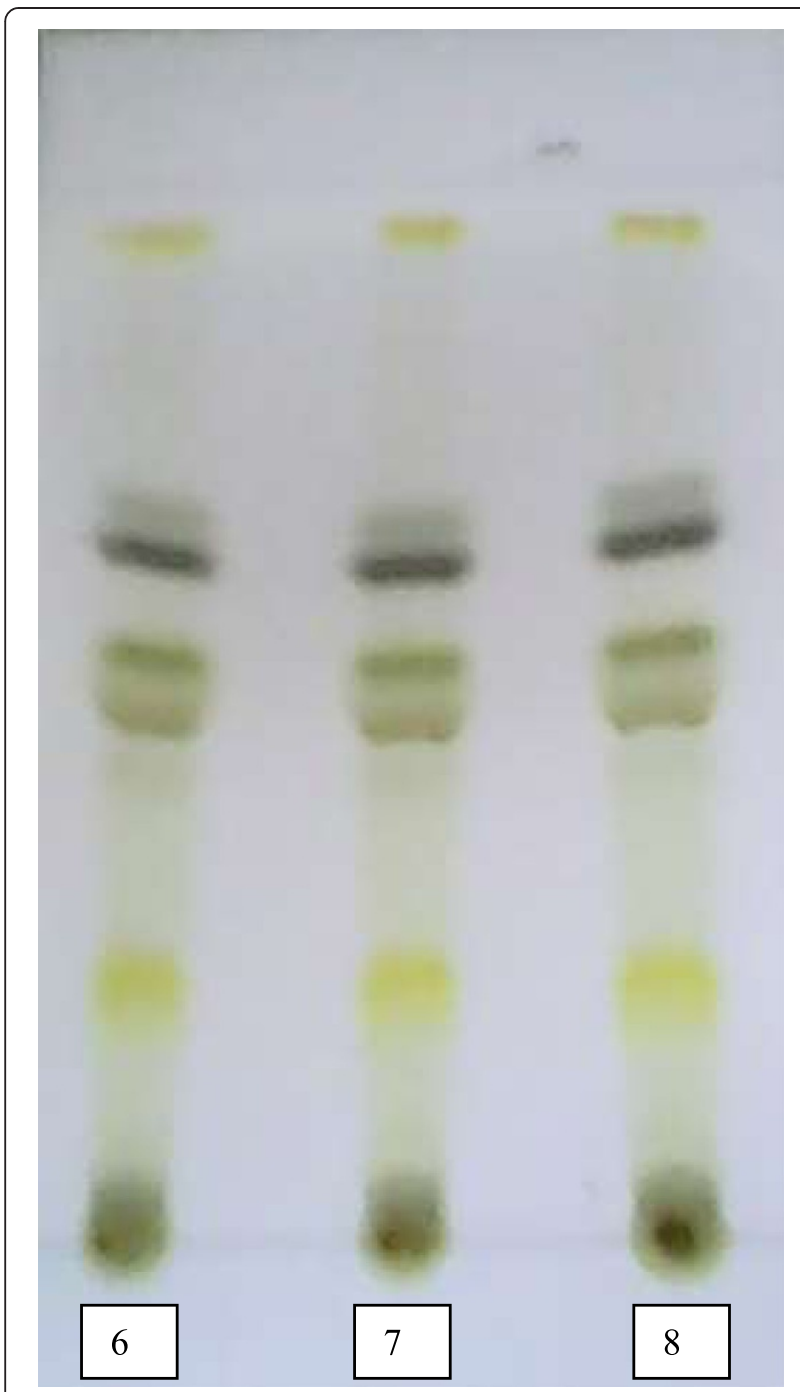

Fig. 1 Typical TLC profile showing different C. zeyheri isolated fractions with similar compounds. Samples 6,7 and 8 are different fractions separated by silica gel column chromatography using $90 \%$ dichloromethane in hexane. The TLC plate was then run using ethyl acetate : hexane (1:3) as the mobile phase

albicans was assessed. Results show that 5-hydroxy-7, 4'-dimethoxyflavone in combination with miconazole exhibited severe growth inhibition than miconazole alone or 5-hydroxy-7, 4'-dimethoxyflavone alone, at all the concentrations tested (Fig. 4).

\section{Time-kill assays}

Synergism was further confirmed with time-kill curves (Fig. 5). Fungistatic effect on the growth of Candida cells was observed for both miconazole and 5hydroxy-7, 4'-dimethoxyflavone at $150 \mu \mathrm{g} / \mathrm{ml}$ and $22.5 \mu \mathrm{g} / \mathrm{ml}$ respectively. The fungistatic activity of these two was transformed to fungicidal by combining them. After only $4 \mathrm{~h}$ of incubation, the combination<smiles>COc1ccc(-c2cc(=O)c3c(O)cc(OC)cc3o2)cc1</smiles>

Compound B: 5-hydroxy-7,4'-dimethoxyflavone.<smiles>COc1cc(O)c2c(=O)c(O)c(-c3ccc(OC)c(O)c3)oc2c1</smiles><smiles>COc1cc(O)c2c(=O)c(O)c(-c3ccc(OC)c(O)c3)oc2c1</smiles><smiles>COc1cc(O)c2c(=O)c(O)c(-c3ccc(OC)c(O)c3)oc2c1</smiles>

Compound C: 3,5,7-Trihydroxyl-3',4'-dimethoxyflavone

Fig. 2 Flavonoids isolated from Combretum zeyheri from Norton, Mashonaland West, Zimbabwe. The flavonoids were characterized as 5-hydroxy-7,4'-dimethoxyflavone and 3,5,7-Trihydroxyl-3',4'dimethoxyflavone. These compounds have been isolated before from other plant species [23-25]

yielded a decrease to zero colonies in comparison to miconazole alone.

\section{Effect of 5-hydroxy-7, 4'-dimethoxyflavone on Candida albicans drug efflux pumps}

The compound, 5-hydroxy-7, 4'-dimethoxyflavone was investigated for its effect on $\mathrm{ABC}$ drug transporters in Candida albicans by measuring the concentration of ciprofloxacin that accumulated in C. albicans in its 


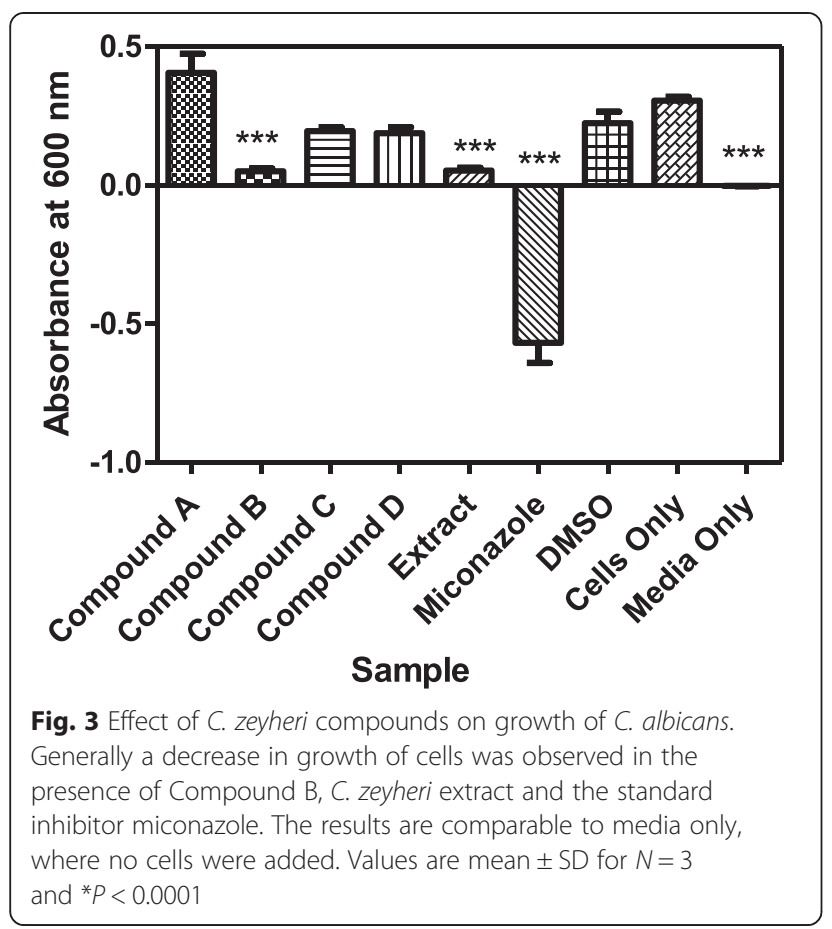

presence (Fig. 6). Glucose was added to provide energy for the drug efflux pumps, therefore, cells which were exposed to glucose only had the least amount of the ciprofloxacin that accumulated in cells since the ciprofloxacin was pumped out of the cells. Cells exposed to 5hydroxy-7, 4'-dimethoxyflavone retained a higher amount of ciprofloxacin, thus, indicating the inhibition of the efflux of the drug from the cells. Reserpine, a

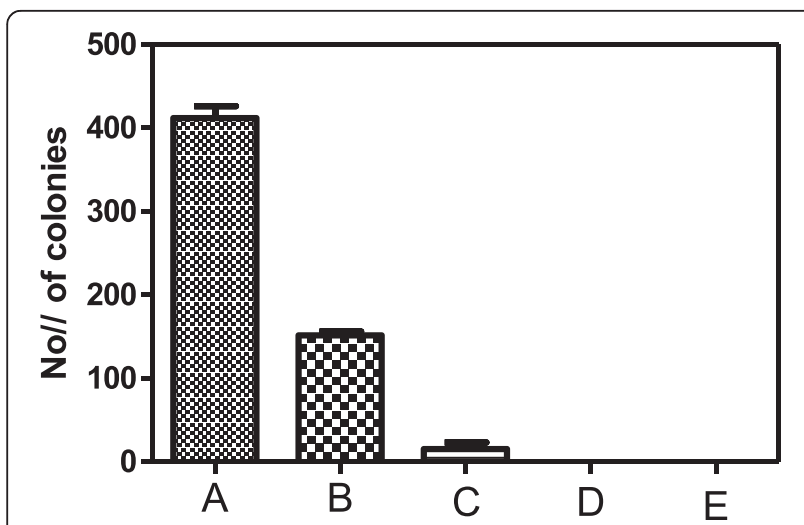

Fig. 4 Synergistic activity of 5-hydroxy-7,4'-dimethoxyflavone-miconazole mixture against C. albicans. (A - 22. $5 \mu \mathrm{g} / \mathrm{ml}$ compound B, B $90 \mu \mathrm{g} / \mathrm{ml}$ compound B, C - $150 \mu \mathrm{g} / \mathrm{ml}$ Miconazole, D - $150 \mu \mathrm{g} / \mathrm{ml}$ Miconazole + $22.5 \mu \mathrm{g} / \mathrm{ml}$ compound B, E - $150 \mu \mathrm{g} / \mathrm{ml}$ Miconazole + $90 \mu \mathrm{g} / \mathrm{ml}$ compound B.) Values are mean \pm SD for $N=3$. Complete inhibition of growth of C. albicans was observed when 5-hydroxy7,4'-dimethoxyflavone and miconazole were combined, unlike when the two were tested on their own standard inhibitor efflux inhibitor showed the inhibition of drug efflux as expected. Thus, further work was carried out to determine the concentration of 5-hydroxy-7, 4'-dimethoxyflavone that reduced the percentage activity of the drug efflux pumps by half, $\mathrm{IC}_{50}$ determination. The $\mathrm{IC}_{50}$ for 5-hydroxy-7, 4'-dimethoxyflavone was found to be $51.64 \mu \mathrm{g} / \mathrm{ml}$ (Fig. 7).

\section{Effects of 5-hydroxy-7, 4'-dimethoxyflavone on ergosterol biosynthesis pathway}

Sterol assay was performed for the mechanistic analysis of the tested drug. Most antifungal drugs target the ergosterol biosynthesis pathway, particularly the enzyme lanosterol 14 $\alpha$-demethylase, and disrupt membrane fluidity, asymmetry and integrity. The effects of 5-hydroxy-7, 4'-dimethoxyflavone on lanosterol 14 $\alpha$-demethylase, was investigated. Figure 8 shows total sterol content of C. albicans treated with $1 / 2$ MIC of 5-hydroxy-7, 4'-dimethoxyflavone at times 16 and 24 hrs of cell incubation. The compound 5hydroxy-7, 4'-dimethoxyflavone showed ergosterol inhibition in C. albicans to 91.6 and $63 \%$ at 16 and 24 hrs respectively, at the tested concentration (Table 1). The decrease in ergosterol in C. albicans could be due to slight inhibition of the ergosterol biosynthetic pathway. Results from Table 1 show a timedependent decrease in ergosterol synthesis as a result of the effect of 5-hydroxy-7, 4'-dimethoxyflavone.

\section{Effects of 5-hydroxy-7, 4'-dimethoxyflavone on antioxidant enzymes}

Candida albicans has evolved enzymatic antioxidant defense mechanisms in order to minimise the damaging effects of ROS produced by phagocytes during an infection, thus 5-hydroxy-7, 4'-dimethoxyflavone was investigated for its effect on these antioxidant enzymes. The activities of the antioxidant enzymes SOD, CAT, GST, GPx, GR and G6PD were investigated spectrophotometrically by measuring change in absorbance of samples in the presence or absence of the compound 5-hydroxy-7,4'-dimethoxyflavone. Specific activities of antioxidant enzymes were then calculated using the extinction coefficients provided for each enzyme and results recorded in Table 2. Results show that $5 \mu \mathrm{M}$ of 5-hydroxy-7,4'-dimethoxyflavone resulted in complete inhibition of activity of the enzymes superoxide dismutase, glutathione peroxidase, glutathione reductase, glutathione-S-transferase and glucose-6-phosphate dehydrogenase. However, treating Candida albicans with 5-hydroxy-7,4'-dimethoxyflavone resulted in roughly a $26 \%$ decrease in activity of the enzyme catalase. 


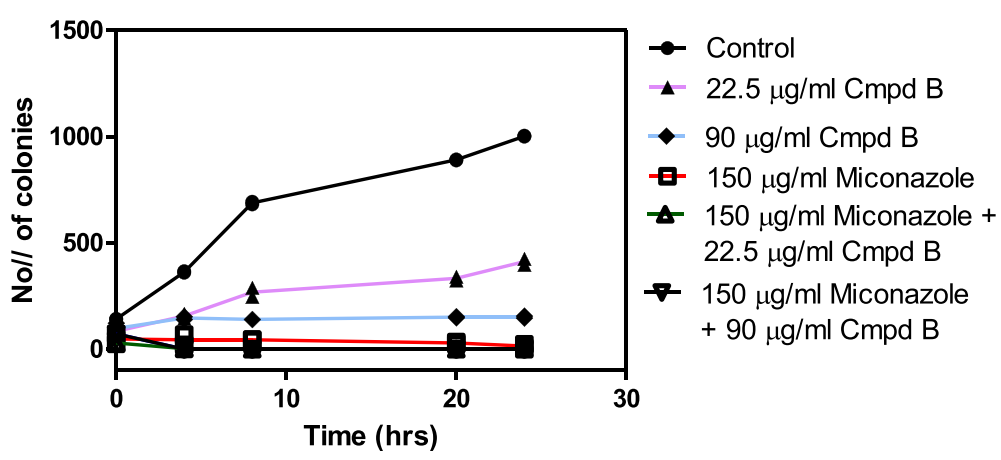

Fig. 5 Representative time-kill curves of Candida albicans following exposure to miconazole, Compond B (5-hydroxy-7,4'-dimethoxyflavone) and miconazole combined with Compound B. Control represents the untreated Candida cells. There was decrease on the rate at which the Candida cells treated with 5-hydroxy-7,4'-dimethoxyflavone-Miconazole mixture were growing as compared to the untreated cells and those treated with miconazole alone or 5-hydroxy-7,4'-dimethoxyflavone alone

\section{Discussion}

Plants have been reported as a valuable source of new natural products despite the availability of different approaches for the discovery of therapeutics. Studies involving the isolation, characterization and purification of the chemical compounds of the plant and screening for antifungal activity have been reported to be more than promising [22]. The assumption for these studies was that they may result in the development of a potent entity

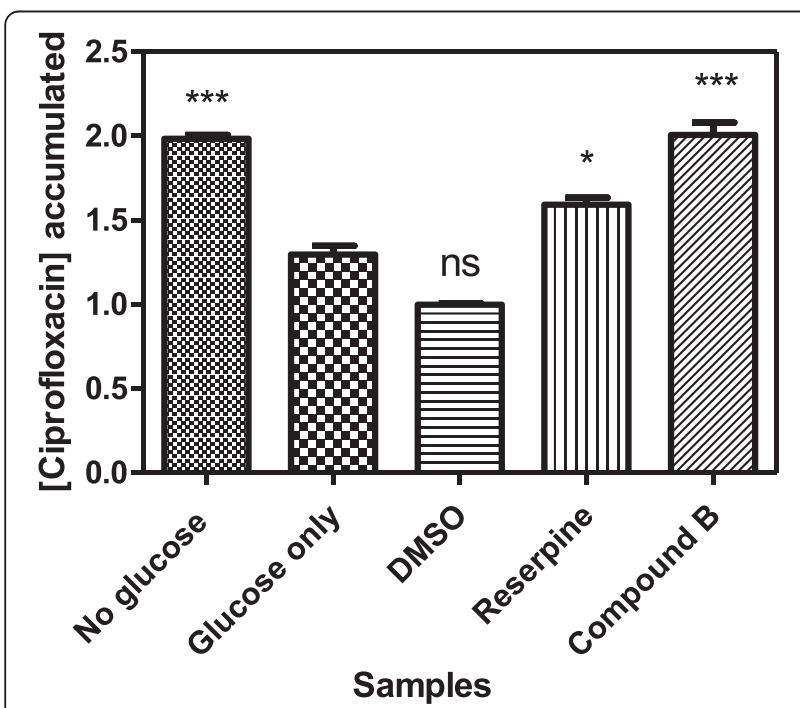

Fig. 6 Graph showing the concentrations of ciprofloxacin that accumulated in C. albicans in the presence of glucose only, DMSO, reserpine and compound B. Values are mean \pm SD for $N=3$ and ${ }^{*} P<$ 0.05. Cells which were exposed to glucose had the least amount of the ciprofloxacin left in the cells, thus, indicating active efflux with glucose serving as a source of energy. Cells exposed to glucose and 5-hydroxy$7,4^{\prime}$-dimethoxyflavone had a higher amount of dye, thus, indicating the inhibition of the efflux of the ciprofloxacin from the cells. Reserpine, a standard inhibitor efflux inhibitor showed the inhibition of drug efflux and DMSO was the negative control and solvent used to dissolve the compound 5-hydroxy-7, 4'-dimethoxyflavone which will be of lower toxicity and a high therapeutic value to mankind. In this current study, the air-dried leaves of $C$. zeyheri were extracted successively with ethanol followed by various chromatographic techniques using different solvents. Subsequent chromatographic assays on silica gel yielded compounds 5-hydroxy-7, 4'-dimethoxyflavone and 3, 5, 7-trihydroxyl-3, 4'-dimethoxyflavone (Fig. 2). The compounds were investigated for their antifungal activity and 5-hydroxy-7, 4'-dimethoxyflavone was found to have an MIC of $45 \mu \mathrm{g} / \mathrm{ml}$ against C. albicans (Fig. 3). This is the first time that the antifungal activity of 5-hydroxy-7, 4'-dimethoxyflavone against $C$. albicans has been reported using the broth dilution assay. The compound 5-hydroxy-7,4'-dimethoxyflavone has already been discovered in the methanol extract of aerial parts of Salvia poculata Nab., a Turkish endemic Salvia species [23] and had showed antioxidant activity using $\beta$-carotene bleaching, and superoxide anion radical and 2,2'-azino-bis(3-ethylbenzothiazoline-6-sulphonic acid (ABTS) cation radical

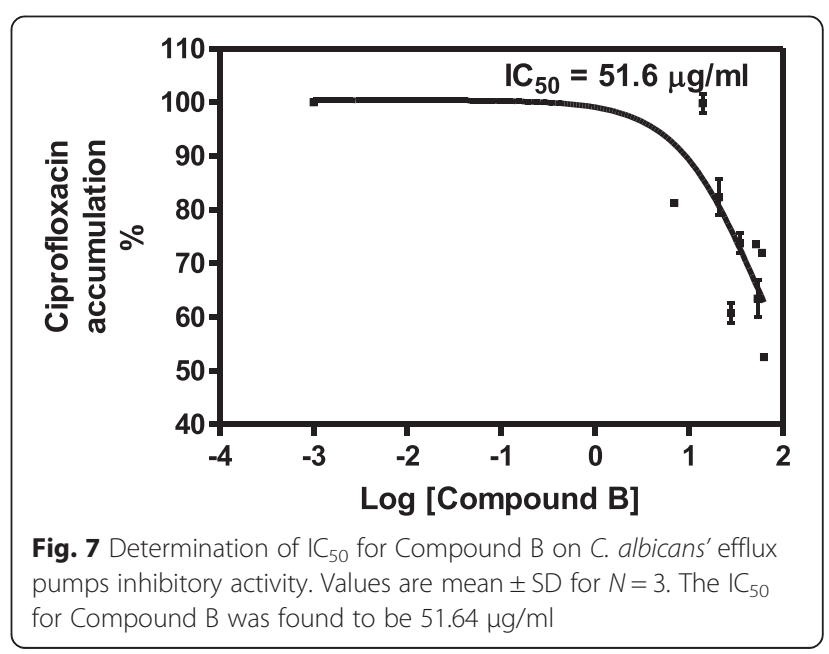




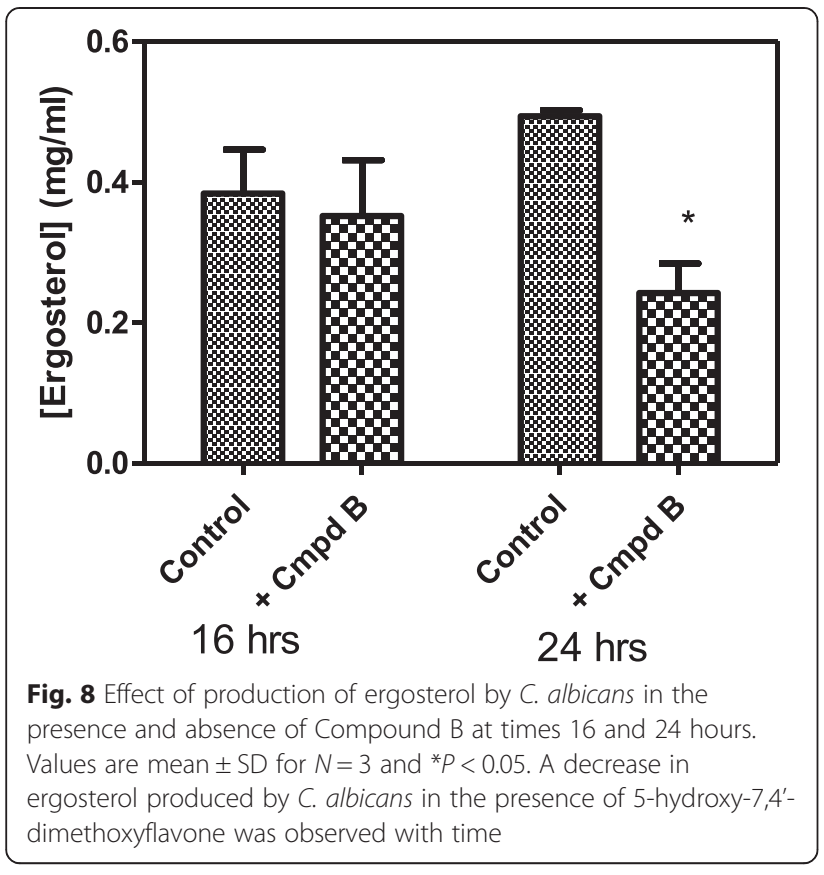

scavenging activity assays. The compound 5-hydroxy-7, 4'-dimethoxyflavone has also been isolated from Combretum erythrophylum and was found to have antimicrobial activity against Vibrio cholerae and Enterococcus faecalis, with MIC values ranging from $25-50 \mu \mathrm{g} / \mathrm{ml}$ [24]. However, the same study found it to be toxic to human cells and to have the poorest antioxidant activity. In another study, 5-hydroxy-7, 4'-dimethoxyflavone was isolated from the rhizome of Kaempferia parviflora, which has been used for the treatment of allergy and gastrointestinal disorders as well as an aphrodisiac and for fungal infections [25]. However, this compound was found to have no antifungal activity against the dermatophytes Trichophyton rubrum, Trichophyton mentagrophytes and Microsporum gypseum at the highest concentration of $250 \mu \mathrm{g} / \mathrm{ml}$ tested. The antifungal activity of this compound was not investigated against $C$. albicans in this same study. Therefore, this current study reports the successful isolation of 5-hydroxy-7, 4'-dimethoxyflavone from $C$. zeyheri leaf extract, which we previously reported to have antifungal activity [11].

Further work was carried out to determine the combined activity of 5-hydroxy-7, 4'-dimethoxyflavone with miconazole since synergism has become a possible

Table 1 Time-dependent effect of 5-hydroxy-7,4'-dimethoxyflavone on ergosterol production by $C$. albicans

\begin{tabular}{lc}
\hline Time of incubation (hrs) & [Ergosterol] \% decrease \\
\hline 16 & 91.6 \\
24 & 63.0 \\
\hline
\end{tabular}

thrust area in developing therapeutic strategies against infectious diseases. The results demonstrated that 5hydroxy-7,4'-dimethoxyflavone is very effective as antifungal agent, as it inhibited C. albicans at $22.5 \mu \mathrm{g} / \mathrm{ml}$ and showed synergy with miconazole as shown by a decrease in growth of $C$. albicans cells in the presence of 5-hydroxy-7,4'-dimethoxyflavone-miconazole mixture as compared to 5-hydroxy-7,4'-dimethoxyflavone alone or miconazole alone (Figs. 4 and 5). Thus, the efficacy of antifungal agents can be improved by using combination therapy where these drugs are administrated along with other chemosensitizing agents.

The isolated 5-hydroxy-7, 4'-dimethoxyflavone was further investigated for its inhibitory activity on $A B C$ drug efflux pumps in C. albicans by monitoring an increase in ciprofloxacin, assessing the level of its accumulation, in response to reserpine. There was a higher accumulation of ciprofloxacin in Candida cells in the presence of 5-hydroxy-7, 4'-dimethoxyflavone than with reserpine (Fig. 6). The compound 5-hydroxy-7, 4'dimethoxyflavone demonstrated the activity in a dosedependent manner with $\mathrm{IC}_{50}$ value of $51.64 \mu \mathrm{g} / \mathrm{ml}$ (Fig. 7). These results support those obtained from synergism assays where by the underlying synergistic antifungal mechanisms could be due to blockage of $\mathrm{ABC}$ efflux pumps and increasing the susceptibility of Candida to miconazole. Further work would be necessary to establish the major mechanism which could be competitive inhibition of drug efflux pumps or non competitive inhibition. It also would be of great interest to determine whether or not 5-hydroxy-7, 4'-dimethoxyflavone can inhibit the activity of other Candida drug transporters such as CaMdr1p belonging to major facilitator superfamily. The study of inhibitors of the drug efflux pumps in Candida species is of great importance but to date only limited in vivo testing has been done and no human toxicology of promising candidates has been performed [26]. The challenges that have so far been reported include that the search for candidate efflux pump inhibitors can be costly and time consuming since substantial efforts are needed before inhibitors of efflux pumps can be used clinically and be fully accepted by the medical community.

This study also focused on investigating the effect of the 5-hydroxy-7, 4'-dimethoxyflavone on the C. albicans ergosterol biosynthesis. Ergosterol biosynthesis is an important target for the development of novel antimycotic drugs, and that of $C$. albicans has been proposed with 14 sterol intermediates resulting in ergosterol and another secondary final compound C-24 ethylsterol [27]. Classes of antimycotics that are curently used to target the ergosterol biosynthesis pathway and disrupt membrane fluidity, asymmetry and integrity are the azoles, allylamines, polyenes, and morpholines [28]. Analysis of 
Table 2 Specific activities of antioxidant enzymes

\begin{tabular}{llll}
\hline Enzyme & Substrate & Specific activity (U/mg protein) \\
\cline { 3 - 4 } & & No compound & $0.253 \pm 0.015$ \\
\hline Glutathone-S-transferase & $\mathrm{CDNB}$ & $1.396 \pm 0.068$ & - \\
Catalase & $\mathrm{H}_{2} \mathrm{O}_{2}$ & $0.204 \pm 0.05$ & $1.031 \pm 0.064$ \\
Superoxide dismutase & Epinephrine & $387.9 \pm 26$ & - \\
Glucose 6 phosphate dehydrogenase & $\mathrm{NADP}$ & $39.77 \pm 4.8$ & - \\
Glutathione reductase & $\mathrm{NADPH}$ & 0.00022 & - \\
Glutathione peroxidase & $\mathrm{NADPH}$ & & - \\
\hline
\end{tabular}

$N=3$

ergosterol obtained from tested Candida albicans showed a time-dependent decrease to $91 \%$ and $63 \%$ at 16 and 24 hrs respectively, in ergosterol content in the cells treated with $1 / 2$ MIC of 5-hydroxy-7, 4'-dimethoxyflavone (Fig. 8 and Table 1). This study supports the work which previously showed that most of the ergosterol inhibitors were fungicidal in its action [29]. This could be due to direct damage to the cell membrane. However, the exact mode of action 5-hydroxy-7, 4'dimethoxyflavone need to be elucidated. Further studies with a higher number of azole-resistant strains should help elucidate whether 5-hydroxy-7, 4'-dimethoxyflavone maintains a good level of activity in all cases. If this is the case, 5-hydroxy-7, 4'-dimethoxyflavone, alone or in combination with azoles, could represent an alternative for the treatment of $C$. albicans infections.

Antioxidant enzymes have a role in the protection of C. albicans against oxidative stress, thus, inhibition of these enzymes by 5-hydroxy-7, 4'-dimethoxyflavone may be a step toward the search for new targets for antifungal agents. The results obtained in this study showed complete inhibition of the activity for all the enzymes tested except for catalase which showed a decreased activity in the presence of 5-hydroxy-7, 4'-dimethoxyflavone (Table 2). However, observed decrease in specific activity or complete inhibition of activity may not be due to direct effects of the compound on enzymes because previously, 5-hydroxy-7,4'-dimethoxyflavone has been reported to have an antioxidant activity, thus, may have quenched the reactive oxygen species before $C$. albicans produced antioxidant enzymes [23].

\section{Conclusion}

The compound responsible for the antifungal activity of the leaf extract of Combretum zeyheri was successfully isolated and characterized as 5-hydroxy-7, 4'dimethoxyflavone.

The mechanism of action of 5-hydroxy-7, 4'-dimethoxyflavone as an antifungal includes inhibition of $C$. albicans' ergosterol synthesis, drug efflux pumps as well as the antioxidant enzymes.

\section{Abbreviations}

MTT: 3-(4,5-dimethylthiazol-2-yl)-2,5-diphenyltetrazolium bromide; SDA: Sabouraud dextrose agar; MIC: Minimum inhibitory concentration; TLC: Thin layer chromatography; ABC: ATP binding cassette; OD: Optical density; BSA: Bovine serum albumin; ATCC: American type culture cell; CDNB: 1-Chloro-2,4-dinitrobenzene; DMSO: Dimethyl sulfoxide; EDTA: Ethylenediaminetetraacetic acid; $I_{50}$ : Half maximal inhibitory concentration; SOD: Superoxide dismutase; GST: Glutathione-s-transferase; CAT: Catalase; GR: Glutathione reductase; G6PD: Glucose 6 phosphate dehydrogenase; GPx: Glutathione peroxidase; GSH: Glutathione; NADP: Nicotinamide adenine dinucleotide phosphate; $\mathrm{H}_{2} \mathrm{O}_{2}$ : Hydrogen peroxide.

\section{Competing interests}

The authors declare that they have no competing interests.

\section{Authors contributions}

SM was the principal investigator of the study and he also helped in writing and revising the manuscript, JM guided in carrying out some chemical purification of the compounds and structure elucidation in the study and RM performed the study, discussed and evaluated the results under the supervision of SM. RM principally participated in writing the manuscript.

\section{Acknowledgements}

This study was sponsored by the International Foundation in Sciences (IFS), Stockholm, Sweden; Grant Number F/3413-03. Support from the International Science Programs (ISP) through International Programmes in Chemical Sciences (IPICS: ZIM01), Uppsala University, Uppsala, Sweden and the Research Board, (RB72/2011) University of Zimbabwe is also acknowledged. We also acknowledge the assistance by Mr. Chii Godloves Fru (University of Younde, Cameroon) for summarising the NMR data.

\section{Author details}

${ }^{1}$ Department of Biochemistry, University of Zimbabwe, P.O. Box MP 167 Harare, Mt. Pleasant, Zimbabwe. ${ }^{2}$ Department of Chemistry, University of Nairobi, Nairobi, Kenya.

Received: 15 May 2015 Accepted: 10 November 2015 Published online: 14 November 2015

\section{References}

1. Vandeputte P, Ferrari S, Coste AT (2012) Antifungal Resistance and New Strategies to Control Fungal Infections. Int J Microbiol 2012 (713687):126. doi:10.1155/2012/713687

2. Perlin DS (2009) Antifungal drug resistance: do molecular methods provide a way forward? Curr Opin Infect Dis 22:568-573

3. Badiee P, Hashemizadeh Z (2014) Opportunistic invasive fungal infections: diagnosis \& clinical management. Indian J Med Res 139:195-204

4. Carrillo-Muñoz J, Finquelievich J, Tur-Tur C, Eraso E, Jauregizar N, Quindós G, Giusiano G (2014) Combination antifungal therapy: A strategy for the management of invasive fungal infections. Rev Esp Quimioter 27:141-158

5. Paramythiotou E, Frantzeskaki F, Flevari A, Armaganidis A, Dimopoulos G (2014) Invasive Fungal Infections in the ICU: How to Approach, How to Treat. Molecules 19:1085-1119 
6. Jothy S, Zakaria Z, Chen Y, Lau YL, Latha LY, Shin L, Sasidharan S (2011) Bioassay-Directed Isolation of Active Compounds with Antiyeast Activity from a Cassia fistula Seed Extract. Molecules 16:7583-7592

7. Avila E, Serna A, Aguilar F, Lezama R (2009) Cytotoxic Activity of Four Mexican Medicinal Plants. Proc West Pharmacol Soc 52:78-82

8. Maroyi A (2013) Traditional use of medicinal plants in south-central Zimbabwe: review and perspectives. J Ethnobiol Ethnomed 9:31

9. Fyhrquist $P$, Mwasumbi L, Haeggstrom CA, Vuorela $H$, Hiltunen $R$, Vuorela P (2002) Ethnobotanical and antimicrobial investigation of some species of Terminalia and Combretum (Combretaceae) growing in Tanzania. J Ethnopharmacol 79:169-177

10. Mangoyi R, Mukanganyama S (2011) In Vitro Antifungal Activities of Selected Medicinal Plants from Zimbabwe against Candida albicans and Candida krusei. The African Journal of Plant Science and Biotechnology 5:1-7

11. Mangoyi R, Mafukidze W, Marobela K, Mukanganyama S (2012) Antifungal Activities and Preliminary Phytochemical Investigation of Combretum Species from Zimbabwe. Microbial and Biochemical Technology 4:037-044

12. Masoko P, Eloff JN (2006) Bioautography indicates the multiplicity of antifungal compounds from twenty-four southern African Combretum species (Combretaceae). Afr J Biotechnol 5:1625-1647

13. Spjut RW: World Botanical Associates Plant Collections for Antitumor Screening: Review of plants collected for antitumor screening. 2010, 1: 48

14. Boora F, Chirisa E, Mukanganyama S: Evaluation of nitrite radical scavenging properties of selected Zimbabwean plant extracts and implications for antioxidative uses in food preservation. 2014

15. Lowry OH, Rosebrough NJ, Farr AL, Randall RJ (1951) Protein measurement with the Folin phenol reagent. J Biol Chem 193:265

16. Habig W, Pabst MJ, Jakoby WB (1974) The first enzymatic step in mercapturic acid formation. Glutathione-S-transferase. J Biol Chem 249:7130-7139

17. Luck H: Catalase. pp. in H.U. Bergmeyer (Ed): Verlag Chemie and academic pres. Weinheim, New York. 1963, 885-888

18. Misra, HP: Handbook of Methods for Oxygen Radical Research, ed Greenwald, R. A. (CRC, Boca Raton, FL), 1985, 237-241

19. Carlberg I, Mannervik B (1985) Glutathione reductase. Methods Enzymol 113:484-490

20. Mohandas J, Marshall JJ, Duggin GG, Horvath JS, Tiller DJ (1984) Low activities of glutathione-related enzymes as factors in the genesis of urinary bladder cancer. Cancer Res 44:5086-5091

21. Zaheer N, Tewari KK, Krishnan PS (1967) Mitochondrial forms of glucose-6phosphate dehydrogenase 6-phosphogluconic acid dehydrogenase in rat liver. Arch Biochem Biophys 120:22-34

22. Campbell BC, Chan KL, Kim JH (2012) Chemosensitization as a Means to Augment Commercial Antifungal Agents. Front Microbiol 3:79

23. Kolak U, Hacibekiroglu I, Ozturk M, Ozgokce F, Ulubelen A (2009) Antioxidant and anticholinesterase constituents of Salvia poculata. Turk J Chem 33:813-823

24. Martini ND, Katerere DRP, Eloff JN (2004) Biological activity of five antibacterial flavonoids from Combretum erythrophyllum (Combretaceae). J of Ethno 93:207-212

25. Kummee S, Tewtraku S, Subhadhirasaku S, Songklanakarin J (2008) Antimicrobial activity of the ethanol extract and compounds from the rhizomes of Kaempferia parviflora. Sci Technol 30:463-466

26. Lomovskaya O, Watkins W (2001) Inhibition of Efflux Pumps as a Novel Approach to Combat Drug Resistance in Bacteria. J Mol Microbiol Biotechnol 2:225-236

27. Alcazar-Fuoli L, Mellado E (2013) Ergosterol biosynthesis in Aspergillus fumigatus: its relevance as an antifungal target and role in antifungal drug resistance. Frontiers in Microbiology, Fungi and Their Interactions 3:1-6

28. Krauss J, Gratzl C, Sturm V, Müller C, Staudacher V, Schmidt CQ, Bracher F (2013) Synthesis and Biological Evaluation of Novel Alkyl-Imidazolyl Carbinols and their Esters: Potent Antimycotics. Sci Pharm 81:641-650

29. Rajput SB, Karuppayil SM (2013) Small molecules inhibit growth, viability and ergosterol biosynthesis in Candida albicans. Springerplus 2:26

\section{Submit your next manuscript to BioMed Central and take full advantage of:}

- Convenient online submission

- Thorough peer review

- No space constraints or color figure charges

- Immediate publication on acceptance

- Inclusion in PubMed, CAS, Scopus and Google Scholar

- Research which is freely available for redistribution

Submit your manuscript at www.biomedcentral.com/submit 